\title{
THE CITIZEN JOURNEY MAP TO PROMOTE THE NOTION OF UNIVERSAL DESIGN IN THE DIGITALISATION OF DEMOCRATIC PROCESSES
}

\author{
Magali Dubosson, Randolf Ramseyer, Antoine Widmer, Blaise Larpin and Emmanuel Fragnière \\ University of Applied Sciences Western Switzerland (HES-SO Valais-Wallis) \\ Rue de la Plaine 2, 3960 Sierre, Switzerland
}

\begin{abstract}
In this research, we have created a new model called "Citizen Journey Map" by analogy to the "Customer Journey Map" in the context of a voting "digital experience". In order to properly design the citizen's digital journey, it is indeed crucial to understand the cultural and socio-demographic characteristics of the Swiss population and to consider all the stages of the various operational processes leading up to the vote (official announcement of the subject of the vote, opinion formation, role of the media and political parties, social networks, etc.). On the basis of these characteristics identified by field surveys, it is possible, thanks to the possibilities offered by digitization, to apply the principles of universal (or integrative) design and thus take into account the vulnerabilities of the entire population. As a case study here, we concentrate on one part of this citizen journey, which is the reading of the official voting documentation. This reading is all the more difficult for those who are voting for the first time, especially young voters, and those who do not master the national languages (French, German, Italian) perfectly. Digitization helps the reading, via a simple mobile phone or a tablet, by a so-called "augmented reality" process. The official document is thus "increased" or completed by a series of definitions, diagrams, translations, pictograms, etc. that allow a dynamic and simplified reading. This app contributes to civic engagement by promoting political knowledge co-creation. This is an in-progress research since the full-scale experiment that we intended to realize in 2020 has been postponed due the Covid.
\end{abstract}

\section{KEYWORDS}

Augmented Reality, Customer Journey Map (CJM), Service Operations, e-Participation, Social Inclusion, Universal Design

\section{INTRODUCTION}

Digitization affects all sectors of society. However, it is still slow to change our democratic processes since it is very much related to the notion of social rather technological acceptance (Almarashdeh and Alsmadi, 20217; Fragnière et al., 2019). Its benefits have been underlined, however, as it helps unite citizens who want to make their voices heard and to force governments to be more transparent and accountable (Brynjolfsson \& McAfee, 2011).

Presently, our democratic processes are undergoing very intense digitization. Moreover, the scandals in the last US presidential elections and the Brexit vote have highlighted the fragility of our democratic processes. In this regard, Switzerland is an interesting context to study because it is the country with the highest number of popular votes in the world. At the present time, two voting options are available: either the voter goes to the polling station or the voter votes by mail. A third possibility, electronic voting, has recently been approved in Switzerland, after years of testing. Due to recent developments, however, the e-voting process is on hold. In the coming years, it may (or may not) become a fully-fledged voting option, just like the other two options. However, the whole process needs to be rethought to ensure strong social acceptance from all parts of the population, otherwise all these digitization efforts will be useless and will undermine trust in digital technology, which is absolutely necessary. As early as 2005, an article published on behalf of the European Commission called on governments in their digitization process to adopt a more participatory and integrative user- and knowledge-centered approach to deliver greater value to the public. But this first requires an understanding of user needs (Centeno et al., 2005). 
Recent research on the broader notion of customer experience (Kirillova, 2018) shows that only a holistic approach can lead to a consistent assessment of the perceived value of the experience as a whole. This is what we want to do here with our approach to the digitization of democratic processes, i.e. to keep the big picture in mind and ensure that, through universal design (Iwarsson and Ståhl, 2003), no one is left behind. In contrast to trains, for example, where those who are not "connected" cannot have access to the best price, which is unconstitutional. And this is the case for the elderly but also for young people who cannot afford to buy a smartphone.

In this short article, we intend to address the topic of e-voting from the perspective of the entire process (i.e. from opinion making to voting operations), while focusing on the human aspects. In Switzerland, the usual way to shape political opinion is through official documents and the traditional media such as television, the press and, more recently, the Internet. Also, poster and household flyer campaigns run by the various political parties are a major influence on political opinion in Switzerland.

To study the whole process, we suggest the use of a visualization tool called "Customer Journey Map" (CJM) which shows all the stages the customer goes through and to adapt it to the citizen's journey. The aim with the use of this model is to benefit from all the research developments related to the CJM and also, as mentioned above, to have a holistic view of the democratic process when redesigning and digitalizing it. Even though digitization is having an increasing impact on our society, it must ensure that it is done in an inclusive manner for public service and democratic processes.

To illustrate this concept of the citizen's journey as a tool for improving the digitization of democratic processes, we proceed with what we call in service design with a zooming in on a specific point of interaction. We chose to focus on the first of the three conditions identified as the foundations of civic engagement, namely the acquisition and processing of information relevant to opinion shaping (Gordon et al., 2013). These authors also point out that keeping informed and becoming politically literate is an impetus for civic engagement, and that the mere act of remaining informed is already a form of participation as a citizen. Moreover, they note that a significant amount of research has "validated a positive relationship between level of political knowledge and the likelihood of political participation" (Gordon et al., 2013).

Our goal was to develop a prototype to integrate, on the basis of the very austere official voting documents, an augmented reality app to make them easier to read. In order to provide the voter with optimal "augmented reality" navigation, it is necessary to have a good knowledge of the voter's habits and needs. To this end, a first phase of fieldwork was conducted, including interviews with different voter profiles and specific observations of use made by voters of current official documents. In particular, we relied on the findings of two recent qualitative surveys on e-voting (Fragnière et al., 2019) and e-participation (Fragnière et al., 2020) in Switzerland. Based on the collected information collected, a scenario ("storyboard") of the augmented reality experience was drawn around a service blueprinting representing all the possible interactions of the voter with his/her mobile phone as an interface. This pilot project should have been tested full-scale during a communal vote in Switzerland in 2020. Unfortunately, Covid-19 interrupted our developments. In Section 2, we explain the concept of the Citizen Journey Map. In Section 2, we present the developments to date and the future steps of this ongoing research.

\section{FROM THE CUSTOMER JOURNEY TO THE CITIZEN JOURNEY MAP}

We approach here the topic of e-participation and e-voting from an operational process perspective, focusing on the human aspects. Indeed, the different steps (also called touchpoints) leading to the final vote are based on an operative process, except that most of the stages are dematerialized, since they are digitized. We then speak of a digital process.

The Customer Journey Map (CJM) is a visualization tool. Based on previous research, Følstad and Kvale (2018) defines Customer Journey as "the processual and experiential aspects of service processes as seen from the customer viewpoint. It is described as the repeated interactions between a service provider and the customer, as an "engaging story" about the user's interaction with a service, or as a walk 'in the customer's shoes' ". It presents the different stages from the beginning to the end of a given service experience. The example in Figure 1 shows (in the upper part) a simplified generic case study of a customer journey in the tourism sector. The aim of the CJM is to get inside the customer's head and visually capture as much as 
possible of what he or she sees, does, perceives or feels. In this example, first of all, a customer chooses a destination using our smartphone, buys the transportation tickets and books the hotel room. Then we describe the journey to the room, where the vacation really begins. The CJM is therefore a visual projection of the customer's perception as $\mathrm{s} / \mathrm{he}$ moves from one touchpoint to another, from the very beginning to the completion of the customer experience (Moon et al., 2016).

Let's now consider the citizen's experience, which is represented in our approach as the citizen's journey map (let's call it the CiJM to avoid confusion with the CJM).
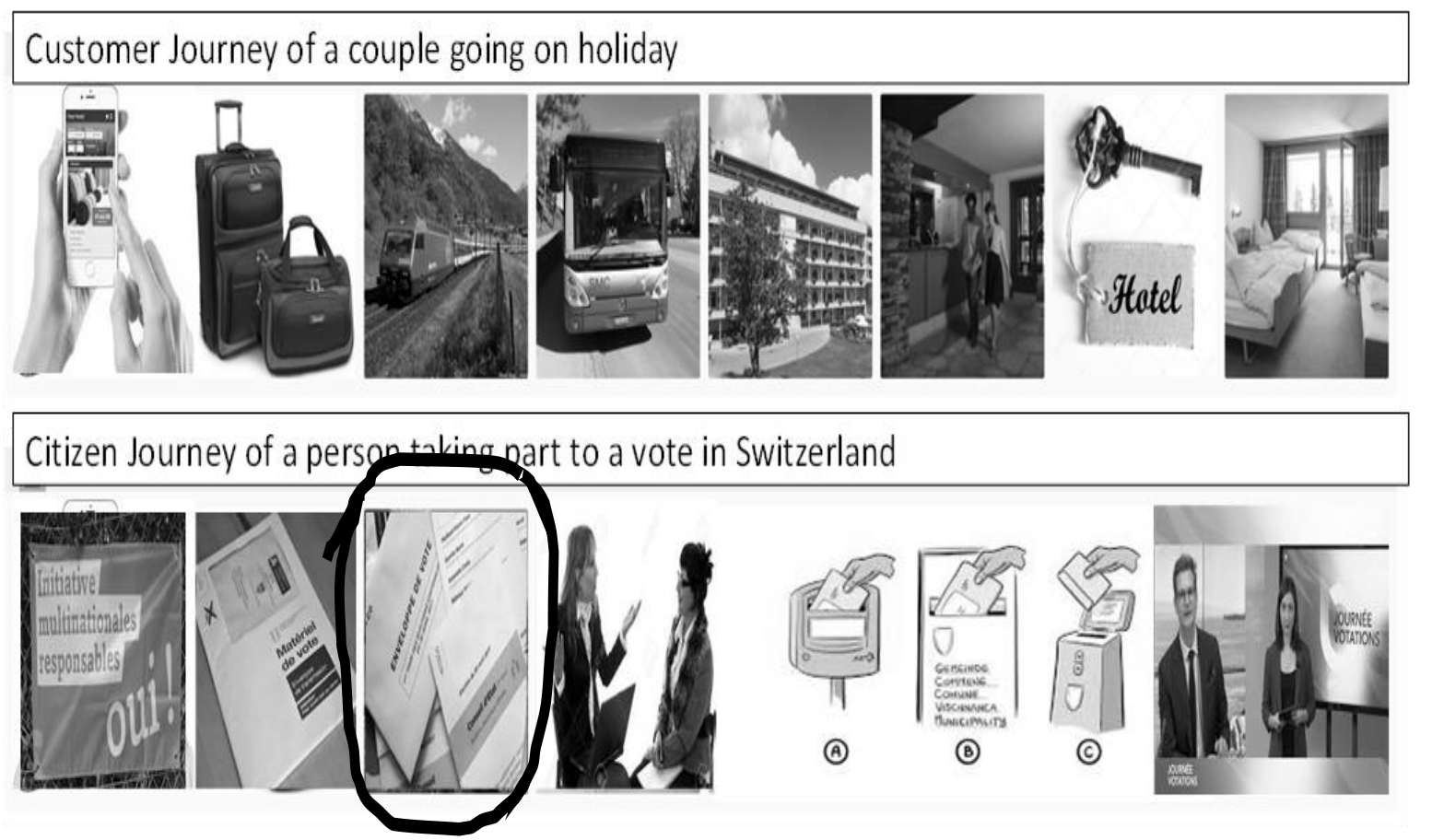

Figure 1. Conceptualization of the Citizen Journey based on the concept of Customer Journey with the aim of facilitating the digitization of democratic processes

In Switzerland, the traditional Citizen Journey of a popular vote consists of a preparation period that can be quite long (about 3 months) in which parties and the media contribute to the formation of voters' opinions. In Figure 1 (in the lower part), we show a typical CiJM that starts with the announcement of a new vote. People entitled to take part to this vote receive an envelope at home containing voting materials as well as documentation from the government and the different parties to form a personal opinion. On this basis and, following discussions and debates on the subject with friends, the citizen will reach an own conclusion. Thus, the citizen will be able to vote. Voters send their ballot papers by post in advance or go to a polling station. Electronic voting is not yet available, although it is an official way of voting.

\section{IMPROVING THE CITIZEN JOURNEY OF THE NON-FRANCOPHONE POPULATION}

We suggest to use here a technique called "zoom in/zoom out". In Figure 1, we have circled the stage where the voter, after having opened his or her voting envelope, consults the official voting documentation. We will focus on the digitization of this step according to the principle of fully inclusive design so that non-French speakers (foreign residents with the right to vote) can clearly understand this documentation (see then Figure 2). This innovation should also benefit to any kind of voter (for example, a young person who has never voted before). Zooming out then makes it possible to get an overall view of the process and thus to have this holistic approach so important to provide meaningful democratic engagement. The "Augmented paper voting" would provide this information in a context-sensitive way, throughout the entire voting process. 


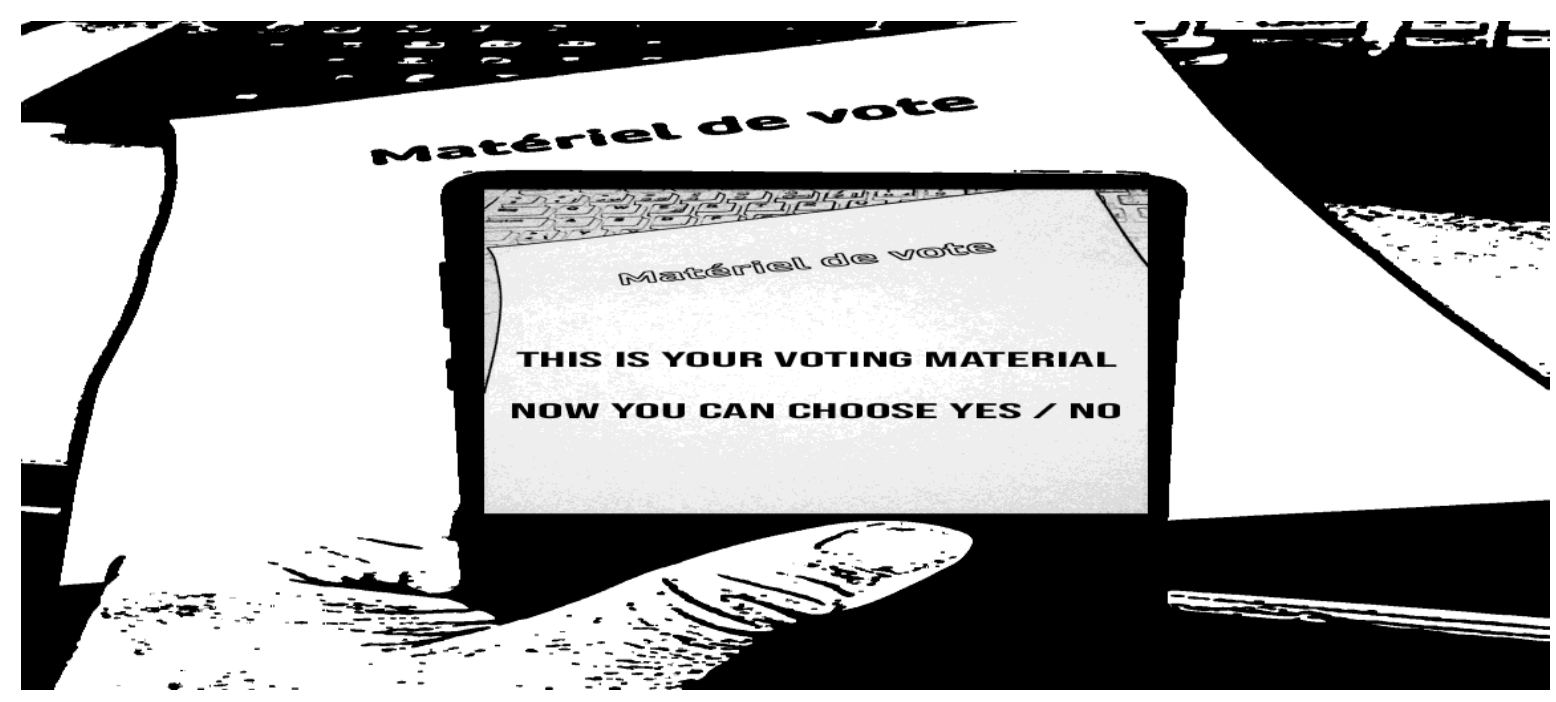

Figure 2. Illustration of the augmented reality app, which allows voters to switch to another language as well as receive didactic information about the respective vote

We have developed a low-fi interface app, which reads the paper envelope and presents information about the voting process. The app interacts with different elements of the voting material and presents for each element additional information, the stage of the process, its role, etc., thus accompanying the voter throughout the process. One of the problems we are trying to solve here with this pilot project is the possible lack of knowledge to vote for foreigners who are entitled to vote at the communal level in certain Cantons of Switzerland. However, they may not have the necessary knowledge to do so and especially, to do it in an easy way while being fully informed to exercise this right according to their real opinion. Currently, this problem is solved through information and discussion sessions, documents (leaflets, etc.) offered by associations representing the countries of origin of these voters. However, this does not guarantee that the process is performed in a optimal and neutral manner.

Various technical aspects had to be addressed in order for the system to be accepted not only legally but also socially by the public, in particular:

- the app should a priori be open source so that it is financially accessible to all language communities;

- $\quad$ official visual identity must be compatible with IT development and subsequent updates;

- $\quad$ and above all, data protection must be guaranteed in compliance with the Federal Act on Data Protection.

Many tests will then have to be carried out, because even if this type of application is not as sensitive as electronic voting per se, in these very hectic times, and with the goal of ensuring everyone's integration, there is no room for error when the application is officially launched. The list below shows the different steps we have taken so far while the last ones are expected to be completed in the middle of 2021:

1. Exploration (fieldwork, literature research, interviews, observations): this stage was carried out in 2019

2. Scripting of the Citizen Journey Maps (CiJM) related to the different voting contexts

3. Zooming in on the touchpoint "Getting acquainted with official voting material"

4. Elicitation of voters' needs for the development of the UX component based on two qualitative surveys on e-voting (Fragnière et al., 2019) and e-participation (Fragnière et al. 2020)

5. Prototyping of the digital application (tablet and/or smartphone), in 2D (to minimize costs) to help non-French speaking people to vote (lo-fi prototype already realized, see Figure 2)

6. Staging and testing of the hi-fi prototype in a realistic setting (test due to be realized in 2021)

7. Production and monitoring of a full-scale experiment during the entire voting phase (hopefully before end of 2021, at the occasion of a communal vote in Switzerland) 
We believe that a citizen journey should allow all voters, regardless of their initial level of knowledge or the language spoken, to easily reach a sufficient level of knowledge to exercise their right to vote. To do this, in a digitalized world, they must be able to get comfortable with the digital processes they already practice in the banking or in the hotel industry, for instance. In this paper, we have shown how augmented reality can help non-French speaking voters to read official voting documentation and thus be better involved in the democratic process. In this context, we can consider that the information delivered is an incomplete service to which the citizen adds functionalities thanks to the application of augmented reality according to his needs and desires (Davies \& Ng, 2015).

We intended to conduct a test for non-French speaking voters in order to support them with our pilot project in spring 2020. This experiment was postponed because of Covid-19. We intend to carry out this this test and ultimately a full-scale experiment in a communal vote in Switzerland by the end of year 2021. The last phase of our research will focus on making recommendations using service design and UX techniques to improve the quality of the "citizen's journey" in terms of involvement in democratic processes. The concept of CiJM can be a powerful tool in delivering a value co-creation experience in a digitalized inclusive society.

\section{REFERENCES}

Almarashdeh, I. and Alsmadi, M.K., 2017. How to make them use it? Citizens acceptance of M-government. Applied Computing and Informatics, Vol. 13, No. 2, pp.194-199.

Brynjolfsson, E., and McAfee, A. 2011. Race against the machine: how the digital revolution is accelerating innovation, driving productivity, and irreversibly transforming employment and the economy.

Centeno, C., van Bavel, R. and Burgelman, J.C. 2005. A Prospective View of e-Government in the European Union. The Electronic Journal of e-Government, Vol. 3, No. 2, pp. 59-66.

Davies, P., and Ng, I. 2015. Moving towards the incomplete: A research agenda for the development of future products in the digital economy. Procedia Manufacturing, 3, 3368-3374

Følstad, A., \& Kvale, K., 2018. Customer journeys: A systematic literature review. Journal of Service Theory and Practice. Vol. 28 No. 2, pp. 196-227.

Fragnière, E., Grèzes, V., Hofstädter, M., Juon, D., Seppey, S., and Ramseyer, R., 2020. Assessing a digitalised citizen consultation platform based on a qualitative survey. In Proceedings of the 18th International Conference e-Society 2020. Sofia, Bulgaria, pp. 129-149.

Fragnière, E., Grèzes, S., \& Ramseyer, R., 2019. How do the Swiss Perceive Electronic Voting? Social Insights from an Exploratory Qualitative Research. In International Joint Conference on Electronic Voting. Springer, Cham, Switzerland, pp. 100-115.

Gordon, E., Baldwin-Philippi, J., and Balestra, M. 2013. Why we engage: How theories of human behavior contribute to our understanding of civic engagement in a digital era. Berkman Center Research Publication, Vol. 21, pp. 1-29.

Kirillova, K., 2018. Phenomenology for hospitality: theoretical premises and practical applications. International Journal of Contemporary Hospitality Management, Vol. 30, No. 11, pp. 3326-3345.

Iwarsson, S., \& Ståhl, A., 2003. Accessibility, usability and universal design—positioning and definition of concepts describing person-environment relationships. Disability and rehabilitation, Vol. 25, No. 2, pp. 57-66.

Moon, H., Han, S. H., Chun, J., and Hong, S. W. 2016. A design process for a customer journey map: A case study on mobile services. Human Factors and Ergonomics in Manufacturing \& Service Industries, Vol. 26, No. 4, pp. 501-514. 